\title{
A Modified Flood Severity Assessment for Enhanced Decision Support: Application to the Boscastle Flash Flood of 2004
}

\author{
S. J. Murray, A. D. Smith, And J. C. Phillips \\ School of Earth Sciences, University of Bristol, Bristol, United Kingdom
}

(Manuscript received 10 April 2012, in final form 26 May 2012)

\begin{abstract}
A modified flash flood severity assessment is presented, based on scoring a set of factors according to their potential for generating extreme catchment-scale flooding. Improvements are made to the index through incorporation of parameter uncertainties, managing data absence, and clearer graphical communication. The motive for proposing these changes is to better inform flood managers during the development of a flash flood that may require an emergency response. This modified decision-support system is demonstrated for the Boscastle flood of 2004 and other historical floods in the United Kingdom. For Boscastle, the extreme nature of the flood is underestimated, which is likely to be due to the lack of sophistication in weighting flood parameters. However, the proposed amendments are able to rapidly reflect the reliability of a catchment severity rating, which may further enhance this technique as a decision-support tool alongside radar observations of localized storms.
\end{abstract}

\section{Introduction}

Flash floods are among the most pervasive meteorological hazards in the United Kingdom and often pose short-lived, high-magnitude threats to the built and natural environments. Their rapid formation, usually defined in the United Kingdom by a time to peak of $<3 \mathrm{~h}$ (Collier 2007), offers limited opportunities to provide warnings for inhabitants of vulnerable catchments and prepare appropriate flood hazard responses. To facilitate mitigation from the impacts of a potential flash flood, increased lead times are required through improvements in small-scale weather forecasting.

Advances have been made in predictive meteorology for convective storms as a result of developments in monitoring techniques, increasingly fine spatial resolution models, and computer processing power (Hapuarachchi et al. 2011). Current approaches typically involve the use of data ensembles based on a combination of rain gauge, radar, and model contributions for generating quantitative precipitation forecasts (QPFs; Collier 2007; Ramos et al. 2007; Golding 2009). QPFs are now able to be

Corresponding author address: S. J. Murray, School of Earth Sciences, Wills Memorial Bldg., University of Bristol, Queens Road, Bristol BS8 1RJ, United Kingdom.

E-mail: steve.murray@bristol.ac.uk conducted at $<10 \mathrm{~km}$ spatial resolution [with the Met Office supercomputer capable of running forecasts at $1.5 \mathrm{~km}$; Golding (2009)] and $<1 \mathrm{~h}$ temporal resolution using numerical weather prediction (NWP) models that provide lead times of 1-6 h (Hapuarachchi et al. 2011). This approach shows promise in producing improved, probabilistic forecasts of flash flooding (e.g., Villarini et al. 2010). However, in order to ascertain likely impacts at the catchment surface, QPFs require coupling with hydrological flow models, which themselves are heavily dependent on accurate precipitation input data for simulating reliable water depths and peak flow timings (Collier 2007). The current aims of flash flood forecasting therefore include the enhanced understanding and model representation of small-scale meteorological features, further improvement of model spatial resolution, and the improved quantification, constraint, and communication of uncertainty associated with the use of multiple data sources and simulation techniques.

On 16 August 2004, up to $200 \mathrm{~mm}$ of rain fell over the Valency catchment (north Cornwall, United Kingdom) within $4 \mathrm{~h}$, which has been estimated as a 1-in-2000-yr event (Bettess 2005). This resulted in a severe flash flood in the village of Boscastle, with estimated peak flows reaching $180 \mathrm{~m}^{3} \mathrm{~s}^{-1}$ and extensive damage to property and infrastructure. The flood was estimated to have 


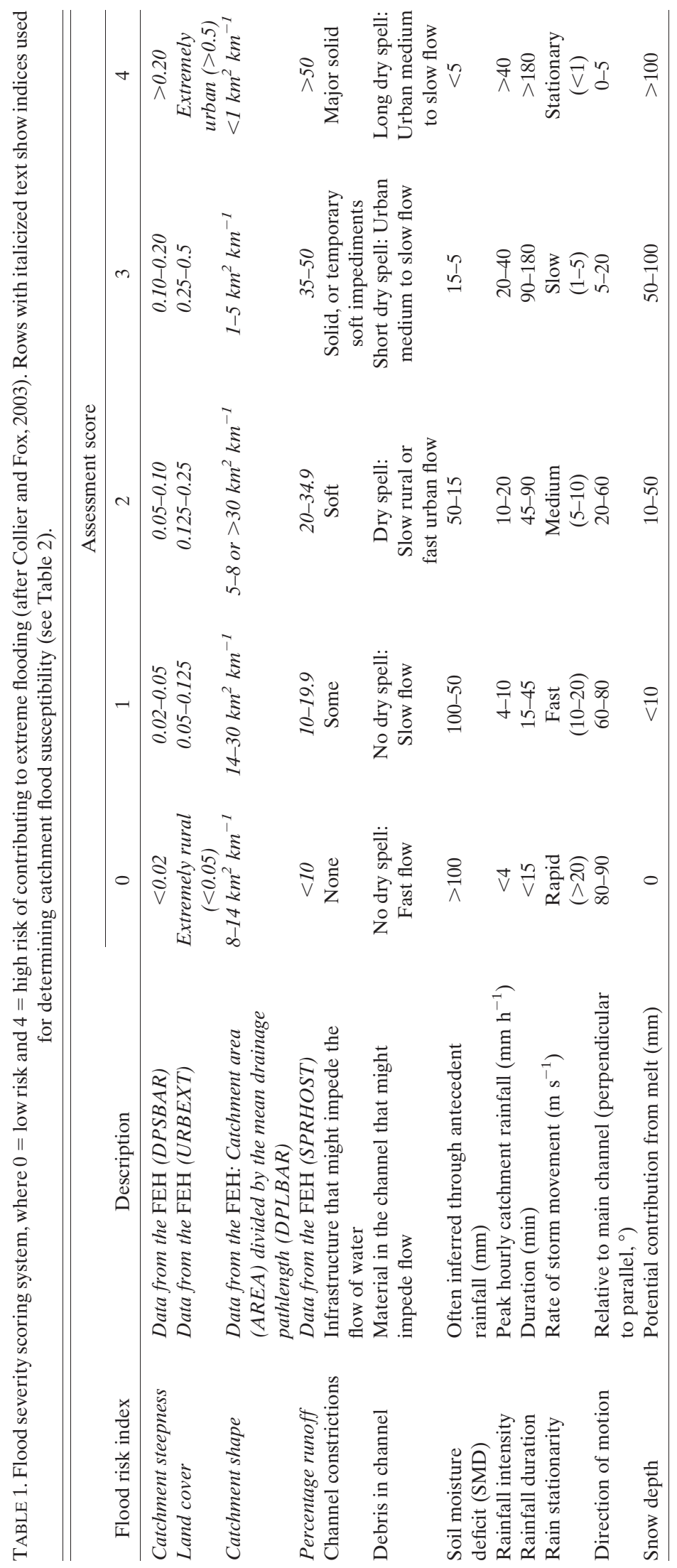


exceeded bankfull discharge for approximately $5 \mathrm{~h}$, with a time to peak of up to $1.5 \mathrm{~h}$. This small, steep, ungauged catchment induces a rapid response to precipitation inputs, which prohibits sufficient lead times for communicating effective flood warnings. Given that reliable flood forecasting and long lead times $(>6 \mathrm{~h})$ for localized convective storms are unlikely to become a practical reality in the near term, catchments vulnerable to flash flooding might alternatively be identified in advance through decision support frameworks (Sene 2008) and used as tools to complement short-term meteorological forecasting.

The rapid onset of highly localized flooding in the Valency catchment meant that specific flood warnings were unable to be provided in the lead up to the event (Guardian, 17 August 2004). In addition, warnings issued for flashy catchments are generally reactive and not preemptive at present, and therefore immediate flood management tends to operate in response to the development of a given storm and the rate of rising river levels. Flood hazard assessments offer an alternative means of rapidly monitoring peak flood risk and may be useful for informing the response to flash floods, particularly during the development of an event. These are typically based on a simple scoring system whereby the contributions to a potential flood from each of its most critical components are regularly evaluated in terms of their "severity." However, there can be weaknesses with such methods and their interpretation, which this paper seeks to address. These include the representation and handling of missing and uncertain data, which may hinder the classification of a flood and thus lead to a potentially misinformed and ineffective response. Amendments are made to the system developed by Collier and Fox (2003) and demonstrated for the 2004 Boscastle flood along with other notable past flood events in the United Kingdom.

\section{Assessing catchment susceptibility and the severity of floods}

The decision support system developed by Collier and Fox (2003) offers a rapid method of assessing catchment susceptibility and extreme flash flood potential through the use of a simple scoring technique (Table 1). Both the underlying vulnerability of a catchment (static parameters; rows 1-4 in Table 1) and the developing meteorological and hydrological conditions are tested (dynamic parameters; rows 5-12 in Table 1). The catchment descriptors (e.g., DSPBAR, SPRHOST) are based on a set of standard parameters defined in the Flood Estimation Handbook (FEH; Institute of Hydrology 1999), but could also be estimated in the field if necessary. Each
TABLE 2. (a) Susceptibility to flash flooding based on catchment morphology (rows 1-4 in Table 1: catchment steepness, land cover, catchment shape, and percentage runoff) (after Collier and Fox 2003). (b) Flood severity classification based on catchment susceptibility, and hydrological and meteorological factors (after Collier and Fox 2003).

\begin{tabular}{lcc}
\hline \hline (a) Flood susceptibility & $\begin{array}{c}\text { Total index } \\
\text { score }\end{array}$ & $\begin{array}{c}\text { Percentage } \\
\text { score }\end{array}$ \\
\hline \multicolumn{1}{c}{ High } & $>8$ & $\geq 50$ \\
$\quad$ Ledium & $7-8$ & $44-50$ \\
& $<7$ & $<44$ \\
(b) Flood severity & Total index & Percentage \\
Extreme & score & score \\
Major & $>30$ & $>63$ \\
Moderate & $20-30$ & $41-63$ \\
Low/flood unlikely & $15-19$ & $31-40$ \\
\hline
\end{tabular}

category is scored between 0 and 4 , with the highest values representing the greatest contribution to flood risk. The aggregate score for each catchment can be used to estimate its baseline flood vulnerability and also as a tool for decision support whereby meteorology and hydrological factors are also incorporated (Table 2); this can be updated in real time during the development of a flood event.

\section{Modifications to the flood hazard index of Collier and Fox (2003) and application to the Boscastle flood}

The main advantages of the aforementioned hazard assessment are the speed and simplicity by which it can be applied, updated, and interpreted during the development of a flood. However, uncertain and missing data are poorly handled at present, and the representation of the index might be improved to assist in the identification of common drivers of flash floods.

\section{a. Communication of flood hazard assessment}

The Collier and Fox (2003) flood hazard assessment is typically reported in tabular format, with the empirical details relating to each index shown along with a total score for each catchment. To provide an "at a glance" view of catchment flood susceptibility classifications, a graphical approach is proposed, color coded according to the level of flood severity of each contributing factor.

\section{b. Missing and uncertain data}

Acquisition of data to satisfy all aspects of the assessment is challenging, both for historical flood events and for floods developing in real time. An end user 
TABLE 3. Retrospective flood hazard assessment for the 16 Aug 2004 Boscastle flood based on the method of Collier and Fox (2003; see Table 1) showing a catchment susceptibility score of $8(50 \%$, indicating medium susceptibility) and a flood hazard score of $24 \pm 2(50 \% \pm 4 \%$, indicating a major event). Rows with italicized text show indices used for determining catchment flood susceptibility (see Table 2).

\begin{tabular}{|c|c|c|c|c|}
\hline Flood risk criteria & Value & $\begin{array}{l}\text { Index } \\
\text { score }\end{array}$ & Reference & Comments \\
\hline $\begin{array}{l}\text { Catchment steepness } \\
(D P S B A R)\end{array}$ & 0.1243 & 3 & $\begin{array}{l}\text { Institute of } \\
\text { Hydrology (1999) }\end{array}$ & \\
\hline Land cover (URBEXT) & 0.007 & 0 & $\begin{array}{l}\text { Institute of } \\
\text { Hydrology (1999) }\end{array}$ & \\
\hline $\begin{array}{l}\text { Catchment shape } \\
\text { (AREA/DPLBAR) }\end{array}$ & $\begin{array}{c}19.98 / \\
4.62=4.32\end{array}$ & 3 & $\begin{array}{l}\text { Institute of } \\
\text { Hydrology (1999) }\end{array}$ & \\
\hline $\begin{array}{l}\text { Percentage runoff } \\
\text { (SPRHOST) }\end{array}$ & 34.48 & 2 & $\begin{array}{l}\text { Institute of } \\
\text { Hydrology (1999) }\end{array}$ & \\
\hline Channel constrictions & Yes & $3-4$ & $\begin{array}{l}\text { Bettess }(2005) \\
\text { Roca and } \\
\text { Davison }(2010)\end{array}$ & $\begin{array}{l}\text { Channel estimated } 90 \% \text { blocked at B } 3263 \\
\text { road bridge by debris including trees and } \\
\text { cars; channel could only contain } 52 \% \text { of } \\
\text { flow even with no blockage; collapse of } \\
\text { 9-ft wall in nearby car park caused water } \\
\text { to surge from the channel along the B3263. }\end{array}$ \\
\hline Debris in channel & Yes & $2-3$ & Golding et al. (2005) & $\begin{array}{l}\text { Likely enhanced mobilization of bank } \\
\text { material due to above average July rain- } \\
\text { fall in the region and } 1-15 \text { Aug } 2004 \\
\text { rainfall } 25 \% \text { above the } 1961-90 \text { average. }\end{array}$ \\
\hline SMD & $40-180 \mathrm{~mm}$ & $0-2$ & Golding et al. (2005) & \\
\hline Rainfall intensity & $85.7 \mathrm{~mm} \mathrm{~h}^{-1}$ & 4 & Burt (2005) & $\begin{array}{l}\text { Peak hourly rainfall measured at Les- } \\
\text { newth }(1450-1550 \text { UTC); estimations } \\
\text { for Otterham and Hendraburnick Down } \\
\text { were } 95-100 \text { and } 125 \pm 10 \mathrm{~mm} \mathrm{~h}^{-1} \text {, } \\
\text { respectively. }\end{array}$ \\
\hline Duration of rainfall & $4 \mathrm{~h}$ & 4 & Burt (2005) & $98 \%$ of $24-\mathrm{h}$ Lesnewth total fell in $4 \mathrm{~h}$ \\
\hline Rain stationarity & $10-15 \mathrm{~m} \mathrm{~s}^{-1}$ & 1 & Golding et al. (2005) & $\begin{array}{l}12.5 \mathrm{~m} \mathrm{~s}^{-1} \text { at } 500 \mathrm{mb} \text {, middle of the storm } \\
\text { layer, consistent with observed storm } \\
\text { movement. }\end{array}$ \\
\hline Direction of motion & $290-15=275^{\circ}$ & 0 & Collier (2007) & \\
\hline Snow depth & $0 \mathrm{~mm}$ & 0 & - & \\
\hline Total & & $24 \pm 2$ & & \\
\hline Percentage & & $50 \% \pm 4 \%$ & & \\
\hline
\end{tabular}

should therefore expect to frequently work with missing and uncertain data; however, the current setup does not allow for their straightforward accommodation. Thus, an approach is proposed whereby the flood classification is also based on the percentage scored from indices used (in addition to the index score), so that the estimated flood severity can be rapidly viewed with regard to the quantity of the available input data. Indices shaded gray (representing missing data) allow an end user to quickly gauge the proportion of data used in the scoring and thus the potential reliability of the severity rating.

The quality of the data used in the hazard assessment will also have a direct bearing on the results obtained. Uncertainty can hamper the extent to which reliable and definitive estimates of flood severity classifications can be made. In addition, some input values may vary considerably within a catchment (e.g., soil moisture) or be open to interpretation (e.g., the extent of debris and channel constrictions), which may cause an event to span several flood severity levels. Therefore, uncertain (and variable) data are expressed on the graphs through direct quantification and by blending colors in cases where parameters span more than one flood severity classification. Propagation of uncertainty may result in a given flood event being positioned across the boundaries of flood severity classes, yet this may be beneficial for informing flood managers in preparing multiple response strategies.

\section{c. Application to the 2004 Boscastle flash flood}

The ambiguity associated with attributing scores to certain aspects of the flood event makes the Valency catchment a suitable case for demonstrating the application of the modified index and, in particular, the handling of uncertain data. 


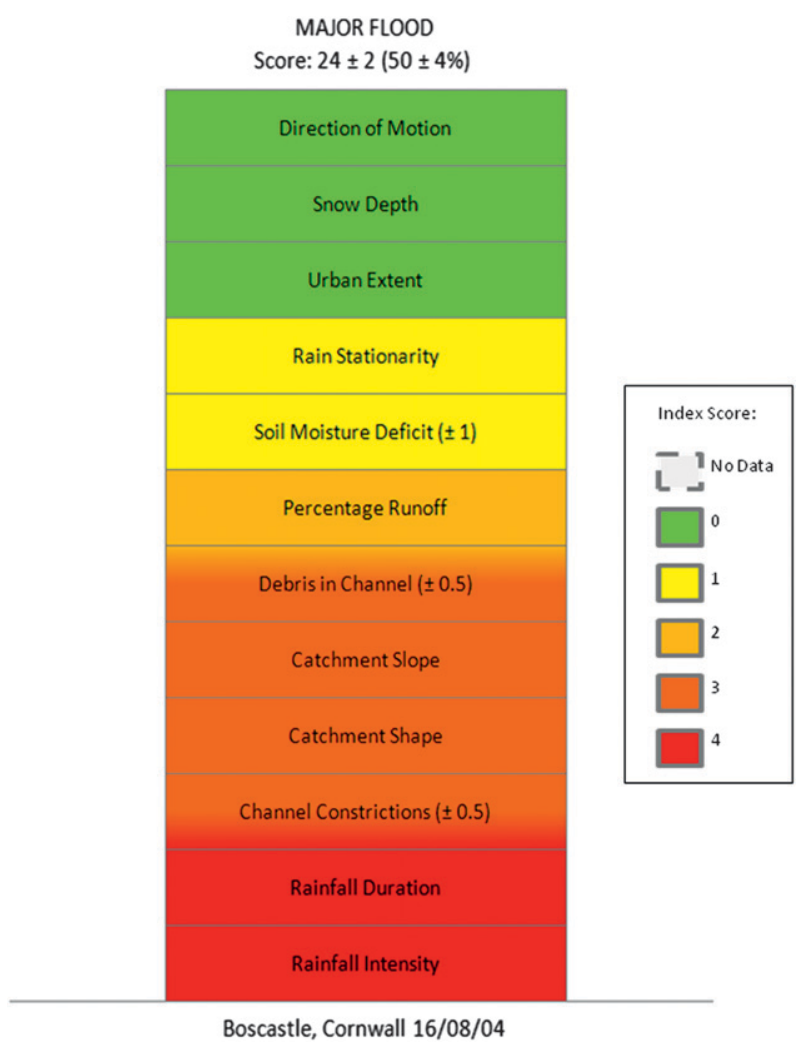

FIG. 1. Constituent components of the hazard assessment for the Boscastle 2004 flood and their individual index scores. For cases where data are uncertain, the central value is plotted.

Despite the flood return period indicating an extreme event, this method of classification suggests the Boscastle flood to have a "major" index score of $24 \pm 2$ (50\% $\pm 4 \%$; Table 3, Fig. 1). This is in agreement with the results of Dale et al. (2004), who assigned the event a score of 28 (due to higher values given to urban extent and rain stationarity). However, both these total scores are likely to be underestimations and highlight a potential limitation of this approach (Collier 2007). Most notably, the index assumes an equal weighting of all contributing factors, which causes the key flood drivers to be largely undistinguished by the scoring system. This approach is also not well suited to representing anomalies. For example, rain stationarity scored 1 for Boscastle due to the rapid movement of the storm. However, model reconstructions simulated the propagation and development of convective cells forming a continuous trail of storm clouds that contributed to the prolonged event (Golding et al. 2005); this feature was unaccounted for in this classification. In contrast, the graphical approach facilitates identification of critical flood factors, while the addition of uncertainty bounds communicates the assertiveness by which individual components were quantified.

\section{d. Application to past flood events}

Application of the modified flood severity assessment is demonstrated using data for past flash flood events from Collier and Fox [(2003); in which details of the individual floods are also provided]. Considering the index scores in concert with other events allows users to assess how robust the estimates are based on the frequency of the nongray bars, while factors common to floods of a given severity rating and within particular geographic regions may also be distinguished.

The added value of the graphical display is apparent in clearly communicating missing and uncertain data (Fig. 2); this may benefit flood managers making decisions during emergency situations. Comparisons between flood events are also facilitated by the color-coding approach relative to the tabulated format. For the events shown, the total score and "flood compositions" among rivers during a given event are generally consistent, with the resultant severity classification only varying by a maximum of one level in each case. All floods classified as "extreme" score 4 for rainfall intensity and duration. In addition, the relative importance of the major contributors to flood events can be assessed rapidly and, for example, shows flooding of the Rivers Barle and Exe (during the 1952 Lynmouth event) to share similar characteristics and "flood profiles" to that of the Boscastle flood.

\section{Discussion and conclusions}

A modified version of the Collier and Fox (2003) flood severity assessment is presented that aims to improve the communication of parameter uncertainties and missing data, so as to more reliably and rapidly inform flood managers during the onset of flash floods. It is tested on the Boscastle flood of 2004 and past events in the United Kingdom. It is proposed that flood severity ratings are assigned based on the percentage score, rather than the sum of the index values, so that missing data do not bias the classifications. Uncertainty is now quantified at the parameter level, which is useful for scoring variable, qualitative, and ambiguous data, and allows the confidence in the flood severity rating to be expressed. A color-coded approach using stacked bars is also suggested (to complement scoring tables), which facilitates communication of the profile for a given flood and comparison between events.

Even with the modification applied, this technique has been shown to be sensitive to anomalies and would appear to underestimate the extreme nature of the Boscastle event. At present, flood contribution scores are also treated equally, irrespective of their relative 
Lynmouth Storm, Devon: 15 August 1952

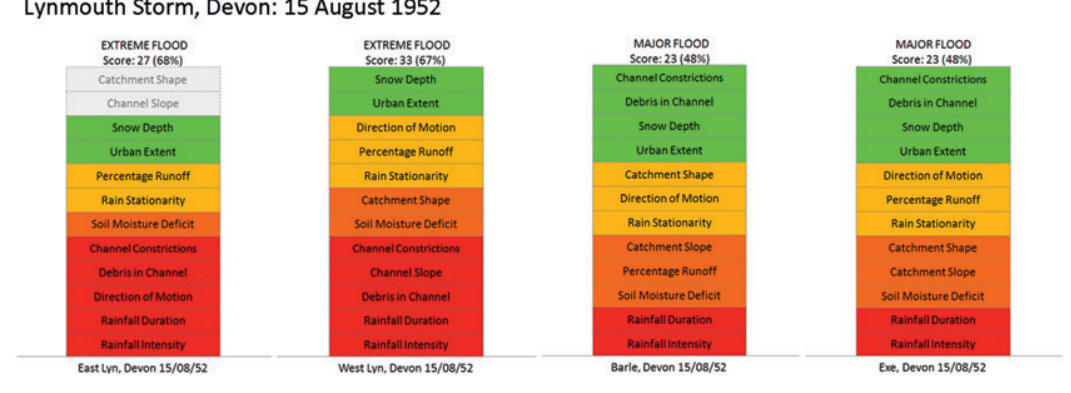

Chew Stoke Storm, Somerset: 10 July 1968

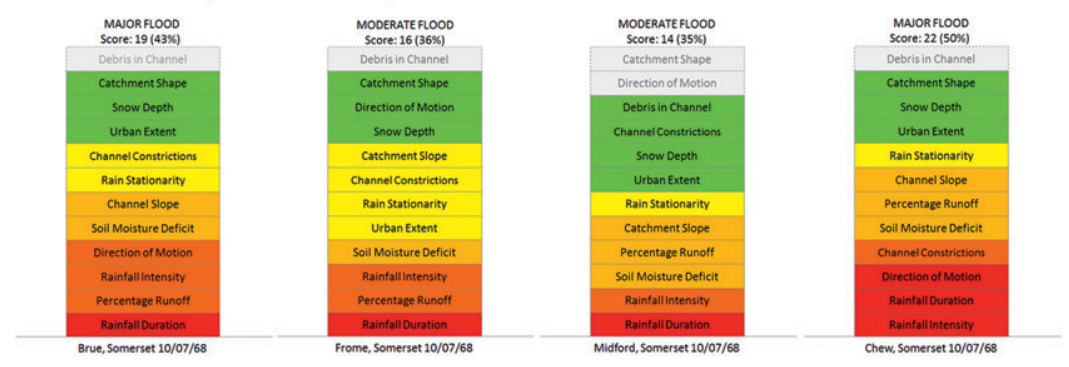

Hampstead Storm, Greater London: 14 August 1975
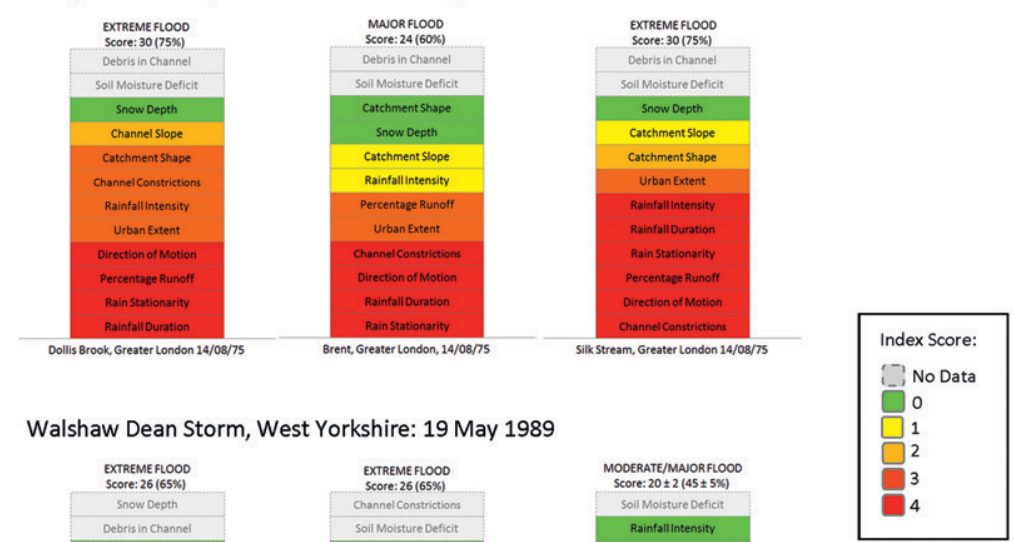

Walshaw Dean Storm, West Yorkshire: 19 May 1989

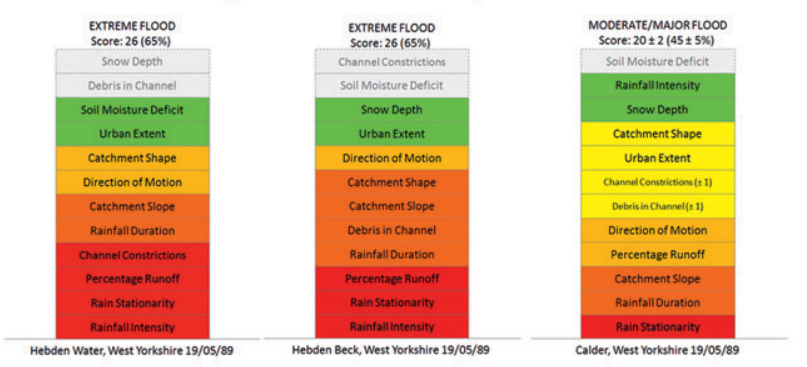

Sleaford Storm, Greater London: 22-23 September 1992

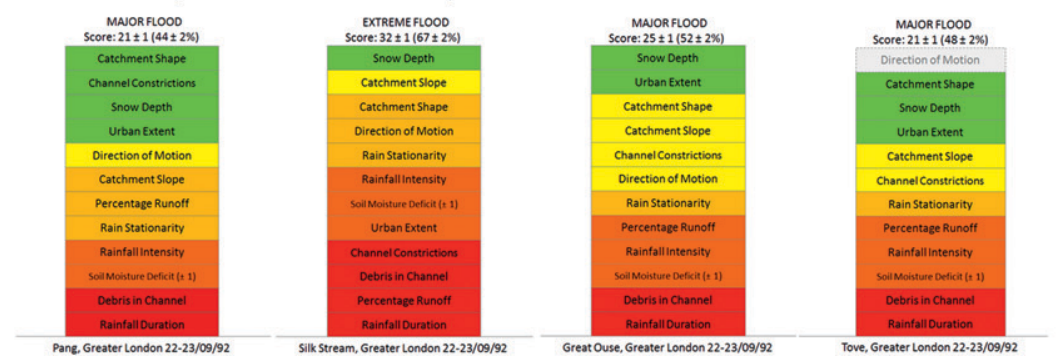

FIG. 2. Modified flood hazard index applied to independently calculated historical flood events as documented in Collier and Fox (2003). 

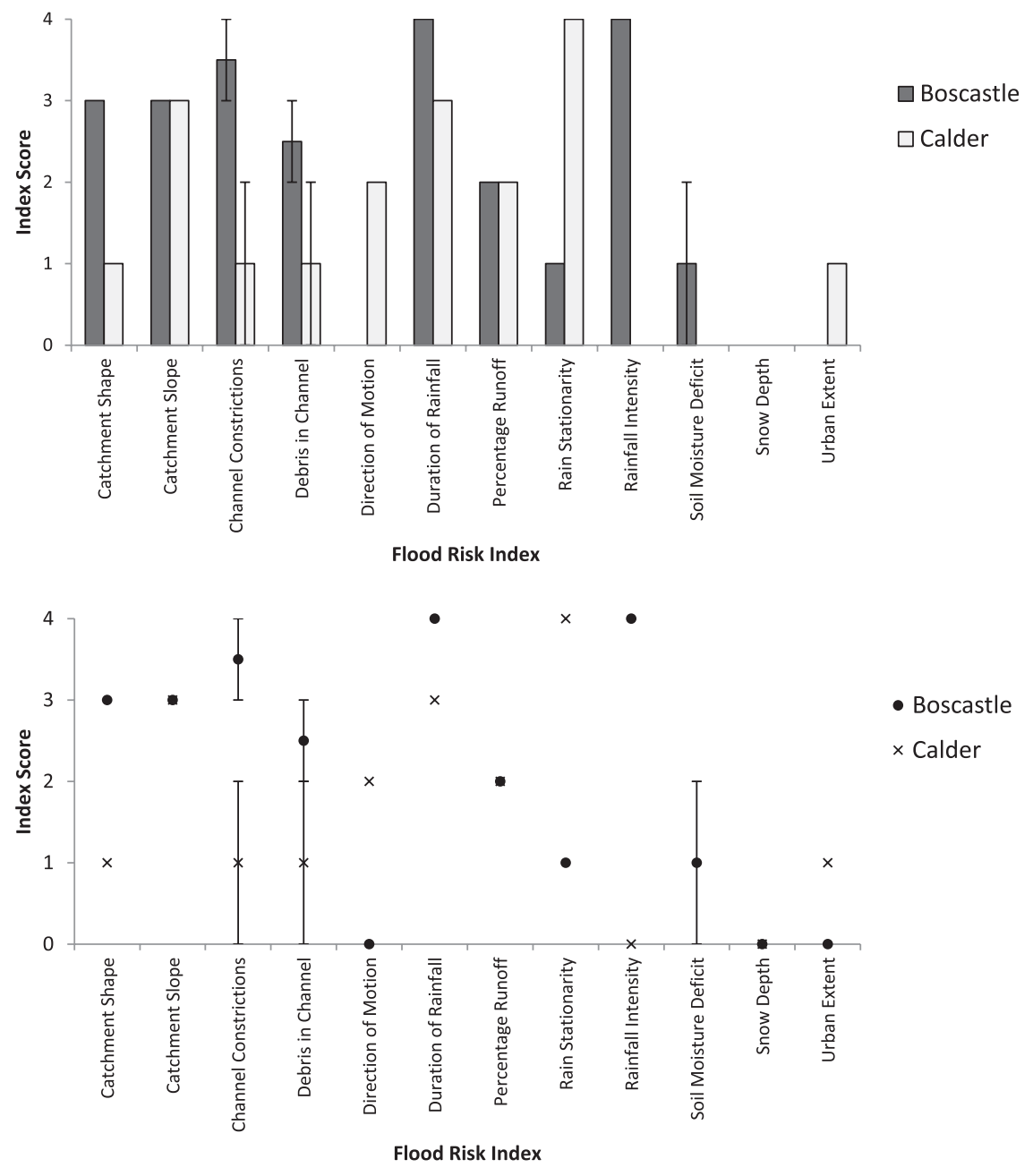

FIG. A1. Modified flood hazard index for the 2004 Boscastle $(24 \pm 2 ; 50 \% \pm 4 \%$-major severity) and the 1989 Calder $(20 \pm 2 ; 45 \% \pm 5 \%$-major/moderate severity) floods represented in (top) histogram and (bottom) scatter graph forms.

importance or frequency of occurrence. This would indicate that future work might focus on weighting flood contributions so as to reflect the extent to which they are critical in producing a given flood severity level.

Overall, the modification described is intended to further aid flood response managers making decisions in highly dynamic circumstances and to be used in tandem with radar observations. Catchment susceptibility metrics might also be applied at the subcatchment scale in order to more precisely identify regions of high vulnerability. However, the assessment can also be applied retrospectively as a means of evaluating features common among historical storms and their scoring profiles. While flash floods are still largely unpredictable and QPFs are still under development, it is hoped that this modified technique may improve decision support and the identification of high-risk catchments during the onset of heavy rainfall.
Acknowledgments. We thank the four anonymous reviewers for their constructive comments on our manuscript. S. J. Murray is the beneficiary of a doctoral grant from the AXA Research Fund. Part of the work reported here was carried out under the auspices of the University of Bristol's MRes in Science of Natural Hazards.

\section{APPENDIX}

\section{Data Communication}

The technique outlined is advantageous largely due to its simplicity. There are, however, some caveats regarding its application, including that the relative importance of flood drivers remains unresolved within each severity class, while the "traffic light" approach may not be best suited for end users with color blindness. 
Alternative forms of graphical communication are demonstrated in Fig. A1 for the Boscastle (2004) and Calder (1989) flood events. While both of these alternative approaches offer improvements in communicating flood hazard relative to the original tabulated format, the clarity, speed, and effectiveness of communication and interpretation is likely to be hindered by their more complex appearance. The histogram approach offers a simple means of directly comparing the characteristics of a small number of historical events, but as the primary objective of this hazard assessment is to determine the likely flood severity of a developing storm, the effective interpretation of individual storm components and the aggregate flood severity classifications take precedence. In addition, the initially proposed traffic-light approach offers the advantage, over both alternative methods, of intuitive communication of data omissions, while also providing clear representation of uncertainty quantifications.

\section{REFERENCES}

Bettess, R., 2005: Flooding in Boscastle and North Cornwall, August 2004. Phase 2 Studies Rep., Contract Report EX5160 to the Environment Agency, HR Wallingford, $170 \mathrm{pp}$.

Burt, S., 2005: Cloudburst upon Hendraburnick Down: The Boscastle storm of 16th August 2004. Weather, 60, 219-227.

Collier, C. G., 2007: Flash flood forecasting: What are the limits of predictability? Quart. J. Roy. Meteor. Soc., 133, 3-23.
— , and N. I. Fox, 2003: Assessing the flooding susceptibility of river catchments to extreme rainfall in the United Kingdom. Int. J. River Basin Manage., 1, 1-11.

Dale, M., P. Dempsey, and J. Dent, 2004: Extreme rainfall event recognition phase 2-Work package 5: Establishing a user requirement for a decision-support tool. Defra/Environment Agency Flood and Coastal Defence R\&D Programme Research and Development Tech. Rep. FD2208, Dept. of the Environment, Food and Rural Affairs, 20 pp.

Golding, B. W., 2009: Long lead time flood warnings: Reality or fantasy? Meteor. Appl., 16, 3-12.

— , P. Clark, and B. May, 2005: The Boscastle flood: Meteorological analysis of the conditions leading to flooding on 16th August 2004. Weather, 60, 230-235.

Hapuarachchi, H. A. P., Q. J. Wang, and T. C. Pagano, 2011: A review of advances in flash flood forecasting. Hydrol. Processes, 25, 2771-2784, doi:10.1002/hyp.8040.

Institute of Hydrology, 1999: Catchment Descriptors. Vol. 5, Flood Estimation Handbook (FEH), Institute of Hydrology, 130 pp.

Ramos, M.-H., J. Bartholmes, and J. Thielen-del Pozo, 2007: Development of decision support products based on ensemble forecasts in the European flood alert system. Atmos. Sci. Lett., 8, 113-119.

Roca, M., and M. Davison, 2010: Two dimensional model analysis of flash-flood processes: Application to the Boscastle event. J. Flood Risk Manage., 3, 63-71.

Sene, K., 2008: Flood Warning, Forecasting and Emergency Response. Springer, $303 \mathrm{pp}$.

Villarini, G., W. F. Krajewski, A. A. Ntelekos, K. P. Georgakakos, and J. A. Smith, 2010: Towards probabilistic forecasting of flash floods: The combined effects of uncertainty in radar-rainfall and flash flood guidance. J. Hydrol., 394, 275-284. 